\title{
PESSOAL
}

\section{Cursos de Administração na Prefeitura do Distrito Federal}

Carlos Eduardo de Oliveira Valle

(Chefe do Serviço de Aperfeiçoamento da P.D.F.)

\section{I - CONSIDERAÇÕES GERAIS}

D Entro do programa de atividades que o Serviço de Aperfeiçoamento da Prefeitura do Distrito Federal pretende cumprir, foi de logo cogitada a questão da necessidade de rever, para adaptação à atual realidade da Administração de Pessoal da Municipalidade, o regulamento referente a cursos de treinamento que, baixado pelo Decreto n. $0^{\circ} 8.115$, de 12 de junho de 1946, ainda hoje vigora, muito embora - diga-se de passagem - não tenha chegado à plenitude sua execução. Algumas tentativas nesse sentido houve - é certo mas não passaram disso. Digna de registro, neste particular, foi a ação do extinto Departamento de Organização que, através da também extinta Comissão de Seleção e Aperfeiçoamento, planejou e chegou mesmo a instalar e executar alguns cursos de administração. A série de alterações profundas e freqüentes de ordem político-administrativa que iria então se suceder, caracterizando-se por uma descontinuidade administrativa, sem precedentes, provocaria o total colapso daquelas atividades que apenas se esboçavam. Houve depois a reintegração do órgão de aperfeiçoamento no exato âmbito de suas atribuições. Estamos nesta fase.

Já tive ocasião de encaminhar às autoridades competentes da Prefeitura dois projetos: um sôbre o regimento interno do Serviço de Aperfeiçoamento e outro sôbre treinamento durante o estágio probatório, visando regulamentá-lo.

Impõe-se agora, como medida inadiável, a revogação do antigo regulamento baixado pelo Decreto n. ${ }^{\circ} 8.115$, antes aludido. O referido regulamento já não serve, positivamente, aos seus propósitos, dentro da atual fase evolutiva da administração de pessoal da Prefeitura.

O novo regulamento que, na forma de ante-projeto, tive a honra de submeter à apreciação superior, fundou-se, em parte, em trabalho realizado, há tempos, pelo Serviço de Planejamento da Prefeitura, contendo, entretanto, as modificações e atualizações que se fizeram de mistér.

O propósito principal, que norteou êsse ante-projeto, no que respeita à endendo: articulação com os órgãos supeiroes da administaçrão municipal, 
e cargos, semelhanças, afinidades e nível de instrução, foi o de centralizar o planejamento e o contrôle dos cursos de treinamento, embora se tenha previsto a descentralização da execução dos mesmos, nos casos em que esta se impuser.

Há uma tendência muito acentuada, hoje em dia, relativamente à instituição de Escolas de Aperfeiçoamento para funcionários civis, semelhante em âmbito e amplitude - ao que ocorre, com êxito absoluto, no seio das fôrças armadas. $E$ óbvio que, de momento, não se poderia cogitar da solução do assunto por aquela forma, sem o perigo de cair no terreno dos planos irrealizáveis. Nada impede contudo que se comecem a formar os núcleos, as células que, orientadas já naquele sentido - como meta futura a atingir - possam representar algo de concreto, de positivo, em têrmos de treinamento.

\section{II - PROGRAMA DE TREINAMENTO E APERFEIÇOAMENTO}

Visando a disciplinar as atividades de treinamento a serem cumpridas pelo Serviço de Aperfeiçoamento da Prefeitura do Distrito Federal, foi estabelecido um plano de ação que, em resumo, consiste no seguinte:

\section{Fase preliminar}

a) Regulamento de estágio probatório;

b) Regimento interno do Serviço de Aperfeiçoamento;

c) Regulamento dos cursos;

d) Instruções gerais sôbre os cursos;

e) Instruções especiais sôbre os cursos;

f) Reuniões de debate (corpo docente e administração);

g) Elaboração do expediente relativo aos atos legais.

\section{Instalação}

a) Levantamento das condições do planejamento e execução (compreendendo: articulação com os órgãos superiores da administração municipal, no sentido de conhecer as necessidades do serviço para efeito de treinamento e o mesmo com relação àqueles órgãos e entidades ou repartições estranhas, com o fim de estabelecer condições para cursos de treinamento, mediante acôrdos ou convênios);

b) recrutamento de professôres;

c) estudo da locação da área para os cursos;

d) pessoal executor (qualitativa e quantitativamente necessário);

e) recrutamento e seleção de alunos;

f) material e equipamento (projetor simples, gravador, livros técnicos, mimeógrafo, máquinas de escrever e material escolar);

§) fixação do critério para início dos cursos (imediatos e mediatos);

h) fixação de data e providências para aula inaugural.

\section{III - REGULAMENTO DOS CURSOS DE TREINAMENTO E APERFEIÇOAMENTO}

Sôbre o novo regulamento que deverá orientar o Setor de Cursos, dentro do programa antes aludido, vale transcrever neste artigo o respectivo anteprojeto por mim elaborado, e concebido nos seguintes têrmos: 


\section{CAPÍTULO I}

\section{DA FINALIDADE}

Art. 1. ${ }^{\circ}$ Os Cursos de Treinamento e Aperfeiçoamento têm por finalidade possibilitar o treinamento e aperfeiçoar os conhecimentos dos servidores da Prefeitura do Distrito Federal.

\section{CAPÍtULO II}

\section{DA ORGANIZAÇÃO DO CURSO}

Art. $20^{\circ}$ Os cursos a que se refere o artigo anterior são grupados em sete secções, correspondentes às seguintes atividades funcionais:

\section{1.a Secção}

A - Funções exercidas primitivamente por profissionais liberais e especialistas.

\section{2.a. Secção}

B - Funções básicas de ensino, de orientação padagógica e administração escolar.

\section{3.a Secção}

C - Funções básicas administrativas.

\section{$4 .^{\mathrm{a}}$ Secção}

D - Funções técnico-profissionais auxiliares.

\section{$5 .^{\mathrm{a}}$ Secção}

E - Funções administrativas auxiliares.

\section{6. ${ }^{\text {a }}$ Secção}

F - Funções artístico-profissionais de regência e de execução musical.

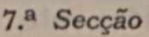

G - Funções profissionais auxiliares.

Art. 3..$^{\circ}$ Secção, para os efeitos dêste Decreto, é o grupamento das atividades principais concernentes aos cargos ou funções segundo as características de semelhança ou afinidade e das respectivas correlações com os propósitos da Administração do Distrito Federal.

Parágrafo único. A Secção compõe-se de Curso Básico, Curso de Treinamento, Curso de Aperfeiçoamento, Curso de Especialização.

Art. 4. ${ }^{\circ}$ O Curso Básico tem por finalidade o ensino ou revisão de conhecimentos gerais ligados ao nível de instrução exigido para o desempenho do cargo ou função.

Art. 5. O Curso de Treinamento visa o ensino de conhecimentos essenciais e práticos necessários ao exercício das atividades funcionais.

Art. 6. $\mathrm{O}$ Curso de Aperfeiçoamento destina-se a aprimorar os conhecimentos ou tnelhorar o nível de instrução específicos próprios da atividade funcional ou daquela que se seguir na hierarquia dos cargos ou funções.

Art. 7. o Curso de Especialização tem por objetivo a formação de especialistas, dentro das atividades específicas de âmbito municipal.

Art. $8^{\circ}$ Os Cursos de Aperfeiçoamento e Especialização compreenderão inclusive: ciclos de conferências, bolsas e viagens de estudo, estágios, seminários e outra modalidade, no país ou no estrangeiro. 


\section{CAPÍTULO III}

\section{DO REGIME DOS CURSOS}

Art. 9. ${ }^{\circ}$ Os cursos são destinados aos servidores da P.D.F., podendo, entretanto, mediiante autorização do Secretário Geral de Administração, ser franqueado a pessoas estranhas.

Parágrafo único. A autorização só poderá ser dada a pessoas estranhas, no caso de não ser atingido por servidores da P.D.F. o número de matrículas fixado.

Art. 10. Os Cursos de cada Secção serão instituídos pelo Secretário Geral de Administração, mediante proposta do Serviço de Aperfeiçoamento do DPS, que determinará a provável clientela, as especializações funcionais, as matérias que deverão ser ministradas e o currículo a ser obedecido.

Parágrafo único. Os Cursos de Treinamento e Aperfeiçoamento podem ser instituídos mediante proposta dos órgãos da P.D.F. após o pronunciamento do Serviço de Aperfeiçoamento da SGA.

Art. 11. A instituição de cada curso será feita mediante Instrução que fixará: - a lotação máxima de cada curso, as condições de inscrição, as disciplinas, os programas, os ciclos, o regime de provas e a duração dos respectivos períodos letivos.

\section{CAPÍtULO IV}

\section{DO INGRESSO E DA MATRICULA}

Art. 12. O ingresso nos cursos far-se-á mediante a observância das normas fixadas neste regulamento e nas instruções específicas complementares que para êsse fim forem baixadas.

Art. 13. A matrícula far-se-á depois de homologada, pelo Secretário Geral de Administração, a classificação oriunda do processo de ingresso, observada a lotação fixada para cada curso.

Parágrafo único. Aos candidatos aprovados nos Cursos Básicos e de Treinamento caberá preferência para efeito de matrícula nos cursos de aperfeiçoamento e especialização.

Art. 14. Uma vez matriculado em qualquer curso o aluno servidor da P.D.F. não poderá desligar-se das obrigações contraídas, salvo em casos especiais a critério do Secretário Geral de Administração.

Art. 15. Será automàticamente eliminado do curso o aluno que:

a) não se submeter ao regime prescrito pelo presente Regulamento e pelas Instruções especiais que venham a ser baixadas;

b) não se sujeitar ao regime disciplinar que fôr estabelecido para os trabalhos dos cursos;

c) faltar mais de $25 \%$ das aulas do curso em que estiver lotado.

\section{CAPÍTULO $\mathrm{v}$}

\section{DA ADMINISTRAÇÃO DOS CURSOS}

Art. 16. Os Cursos serão dirigidos e administrados pelo Serviço de Aperfeiçoamento.

Parágrafo único. Os cursos que por sua natureza, forem realizados fora da SGA, inclusive os que resultarem de convênios ou acôrdos com repartições públicas ou instituições particulares, estarão sujeitos a supervisão do Serviço de Aperfeiçoamento para efeito de recrutamento e contrôle de resultados.

Art. 17. Ao Serviço de Aperfeiçoamento compete:

I - propor normas para funcionamento dos cursos, realização de provas de seleção e de habilitação e verificação dos resultados; 
II - propor, ouvido o corpo docente a orientação pedagógica relativa aos cursos;

III - propor a designação dos professores e do pessoal necessário ao planejamento. e execução dos cursos;

IV - rever os programas do ensino elaborados pelos professôres;

$\mathrm{V}$ - controlar a movimentação de verbas;

VI - controlar a freqüência dós professôres, alunos e pessoal administrativo;

VII - requisitar o material necessário;

VIII - organizar e elaborar o expediente específico dos cursos;

IX - organizar a documentação referente aos trabılhos e estudios realizados.

\section{CAPÍtULO VI}

\section{DOS PROFESSÔRES}

Art. 18. Os Cursos serão ministrados por professôres nacionais ou estrangeiros, admitidos pelo Secretário Geral de Administração como extranumerários-mensalistas; mediante: contrato ou remuneração à razão de aulas dadas, na forma da legislação em vigor.

Parágrafo único. Poderão ser designados professôres funcionários efetivos, interinos ou extranumerários.

Art. 19. Os honorários, por aula, serão fixados anualmente pelo Secretário Geral deAdministração, respeitada a respectiva dotação orçamentária.

Arț. 20. Os cursos pođerão ser regidos por professôres-chefes, professôres e professôres-assistentes.

Art. 21. Os professôres-chefes, além das atividades docentes que the forem atribuídas, serão encarregados de manter a coordenação entre os cursos da secção e de zelar pela harmonia das normas didáticas que deverão ser observadas nos mesmos.

Art. 22. Aos professôres-assistentes, além do exercício normal de coadjuvação, cabetambém a substituição eventual dos professores.

Art. 23. São obrigações comuns a todos os professôres:

a) a estrita observância dos horários de trabalho;

b) a elaboração dos programas, de acôrdo com as normas e instruções; regerem;

c) a responsabilidıde pelo ensino e ordem interna das secções ou disciplinas que-

d) a elaboração, dentro dos processos e modêlos aprovados, do material que deverá ser usado nas provas e verificação de aproveitamento;

e) auxiliaz a aćministração dos cursç, observando e fazendo observar os incisos do. presente regulamento e instruções especiais que forem baixadas pela autoridade competente.

\section{CAPÍtuLo viI \\ DISPOSIÇÕES GERAIS}

Art. 24. Ao aluno que concluir, de acôrdo com as instruções fixadas, um curso de uma secção, será expedido um certificado que indicará as matérias e os graus de aprovação.

-Art. 25. Ao aluno que terminar os cursos de uma secção, expedir-se-á diploma deconclusão de curso, com indicação da secção, das matérias e das notas finais obtidas.

Art. 26. A conclusão dos cursos de uma secção constituirá merecimento para efeito de promoção, devendo, para êsse fim, constar dos assentamentos funcionais pertinentes.

Art. 27. A juízo do Prefeito, por proposta do Secretário Geral de Administração, os. servidores municipais poderão efetuar cursos ou viagens de estudos, no interêsse da repartição ou serviço, dentro ou fora do Distrito Federal, junto a organizações públicas ou privadas, nacionais ou estrangeiras. 
Art. 28. Poderão ser organizados, para efeito de treinamento e aperfeiçoamento do pessoal lotado em serviços e repartições fora do perímetro urbano, cursos de correspondência e pelo rádio.

Art. 29. A juízo do Prefeito, por proposta do Secretário Geral de Administração, poderão ser realizados cursos fora do perímetro urbano, desde que o número de servidores interessados justifique o custo dos mesmos.

Art. 30. O ano letivo será iniciado a 15 de março e terminará a 14 de novembro.

Art. 31. Os casos omissos serão resolvidos pelo Prefeito ou pelo Secretário Geral de Administração, no âmbito das respectivas atribuições.

Art. 32. Dentro de 30 (trinta) dias serão baixadas pelo Secretário Geral de Administração as instruções complementares necessárias à execução dêste Regulamento.

Art. 33. O presente regulamento entrará em vigor na d'ata de sua publicação, revogadas as disposições em contrário.

$$
\begin{gathered}
\because \% \\
\text { IV - CONCLUSÃO }
\end{gathered}
$$

As providências dadas pela superior administração, inclusive no que tange a verbas adequadas para permitir a exeqüibilidade do plano respectivo, deverão ser concretizadas ainda êste ano, esperando-se, pois, para breve, o início regular do programa de treinamento e aperfeiçoamento, traçado na exata conformidade da política de pessoal adotada, que empresta especial relêvo a êsse problema, notadamente no que se refere à sistematização, no setor de cursos, cuja indispensabilidade, na atual conjuntura, por ser demais evidente dispensa maiores comentários.

\section{SUMMARY}

1. The necessity of a reform of the present system of in-service training of the Prefeitura do Distrito Federal (Municipal Government). The rules and regulations in force were enacted in 1946.

2. A plan of reform has been elaborated by the Author. According to such plan new rules and regulations would discipline the matter.

3. The training courses would comprise seven sections, corresponding to the follo ing occupational groups. (1) professional and specialized; (2) educational; (3) adminis. trative; (4) technical and vocational; (5) clerical; (6) artistic; (7) semi-professional. Each section would comprise (1) a basic course, (2) a training course (3) an advanced course and (4) a especialization course.

4. Organization of the courses specified. Norms concerning length of the courses, subject-matter, curricula, programmes, students application, registration, attendance, etc.

5. Statement of the principles of the administration of the courses. Supervision of the courses entrusted to the Serviço de Aperfeiçoamento. Competence of the Serviço analyzed.

6. The teaching staff: heac, teachers, teachers and assistant teachers. Their responsibilities defined.

7. General provisions concerning dip'omas and certificates, as well as privilegos resulting from completion of courses. 